\title{
Phase transformation on mixed yttrium/sodium-MOFs, X-ray thermodif- fractometry and structural modeling
}

\author{
Z. Amghouz*, S. Khainakov, J. R. García, \\ S. García-Granda
}

Departamentos de Química Física y Analítica y Química Orgánica e Inorgánica, Universidad de Oviedo - CINN, 33006 Oviedo, Spain

*Contact-author; e-mail: amghouz.uo@uniovi.es

Keywords: MOFs, X-ray thermodiffractometry, phase transformation, structural modeling

\begin{abstract}
New chiral MOFs, assembled from Y(III), Na(I) and chiral flexible-achiral rigid dicarboxylate ligands, have been obtained as single phase under hydrothermal conditions and their structures were solved by single-crystal XRD. The powder X-ray thermodiffractometry study was performed, and reveals that the dehydration of both compounds is accompanied by phase transformation, while the spontaneous rehydration process is characterized by different kinetics. The crystal structures of anhydrous compounds have been modeled.
\end{abstract}

\section{Introduction}

Metal-organic frameworks (MOFs), also known as coordination polymers, continue receiving a great attention, since they are a very attractive class of materials due to, the great deal of extended structures and to their potential applications in several fields such as gas storage [1,2], catalysis [3], magnetism [4,5], luminescence [6,7], and so on. In the last decade, large variety of bi- or multi-functional organic linkers and transition or rare earth metals units have been applied as building blocks, leading to numerous 2D and 3D structures. Nevertheless, to the best of our knowledge, only some of them exhibit interesting features, such as reversible phase transition [8-10].

Previously [11] we have reported the hydrothermal synthesis and the full structural characterization of two novel chiral yttrium-based metal organic frameworks, both exhibited phase transformation corresponding to the dehydration process. In continuation of this work, and in the aim to determine the structures of the dehydrated forms, powder X-ray thermodiffraction data and the structural modelling have been performed. 


\section{Experimental}

\subsection{Synthesis}

Compounds 1 and 2, formulated as $\mathrm{NaY}\left(\mathrm{C}_{4} \mathrm{H}_{4} \mathrm{O}_{6}\right)\left(\mathrm{C}_{8} \mathrm{H}_{4} \mathrm{O}_{4}\right)\left(\mathrm{H}_{2} \mathrm{O}\right)_{2}$ and $\mathrm{NaY}\left(\mathrm{C}_{4} \mathrm{H}_{4} \mathrm{O}_{6}\right)\left(\mathrm{C}_{14} \mathrm{H}_{8} \mathrm{O}_{4}\right)\left(\mathrm{H}_{2} \mathrm{O}\right)_{2}$, respectively, were synthesized under hydrothermal conditions, and obtained as a single phase of colorless needle crystals, as described in the ref. 11.

\subsection{Powder X-ray thermodiffraction studies}

Powder X-ray thermodiffraction studies were performed in air. The sample was placed in an Anton Paar HTK 1200N oven-chamber, on a PANalytical XPERT-PRO diffractometer, using $\mathrm{Cu} \mathrm{K \alpha}$ radiation, equipped with PIXcel linear detector with 255 channels. Each powder

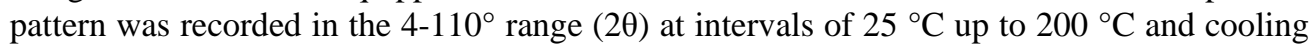
down to $25^{\circ} \mathrm{C}$ with a step of $0.013^{\circ}$ and a counting time of $0.424 \mathrm{~s} / \mathrm{channel}$. The temperature ramp between two consecutive temperatures was $10^{\circ} \mathrm{C} / \mathrm{min}$.

\subsection{Structural modeling}

The structures of $\mathbf{1}$ and $\mathbf{2}$ were used as initial models. After (i) removing the two water molecules (coordinated to sodium atoms), and (ii) using the following initial unit cell parameters, $a=6.7515(5) \AA, b=28.666(6) \AA, c=7.309(1) \AA$, and $a=6.7195(3) \AA, b=37.886(4) \AA, \mathrm{c}=$ 7.5429(6) $\AA$, obtained from the indexation of powder XRD patterns at $200^{\circ} \mathrm{C}$ corresponding, respectively, to dehydrated forms of $\mathbf{1}$ (D1) and $\mathbf{2}$ (D2), and (iii) keeping the fractional coordinates fixed during the lattice changes. The full geometry optimizations of the resulting structures, in the space group $P 1$, were performed in DMOL3 module implemented in Materials Studio [12], by using the local density functional (LDA) of Vosko-Wilk-Nusair (VWN) [13] with a double numerical basis set with polarization functions (DNP) and a "medium" Kpoint set. During the optimization, the unit cell parameters were kept fixed. The structures were considered to be converged when the change in energy between two iterations was smaller than $1.10^{-5}$ hartree and gradient and displacement were, respectively, less than $2.10^{-3}$ hartree $\mathrm{a}_{0}{ }^{-1}$ and $5.10^{-3} \mathrm{a}_{0}$. Between 23 and 66 iterations were required to reach convergence. The symmetry test was performed of the models obtained in $P 1$ for $\mathbf{D} 1$ and $\mathbf{D} 2$, and it was found to be higher, $P 2$, in case of $\mathbf{D 2}$. Rietveld refinement of the obtained models was carried out with Reflex, a powder diffraction module implemented in Materials Studio. The PXRD profiles have been modeled as a pseudo-Voigt function in the range $2 \theta=4-45^{\circ}$. The parameters refined were: the zero offset, the scale factor, 20 background terms, the $\mathrm{U}, \mathrm{V}$ and $\mathrm{W}$ profile parameters, the unit cell parameters, Finger-Cox-Jephcoat asymmetry correction for peaks below $2 \theta=20^{\circ}$, global isotropic temperature factor, and the preferred orientation using March-Dollase function in the directions [010] (for D1) and [001] (for D2). The unit cell parameters and the final values of figures of merit are listed in Table 1.

\section{Results and discussion}

Compounds $\mathbf{1}$ and $\mathbf{2}$ crystallize in the orthorhombic chiral space group C222 $2_{1}$ with unit cell parameters $a=6.8854(2) \AA, b=30.3859(7) \AA, c=7.4741(2) \AA$ for $\mathbf{1}$, and $a=$ $6.8531(2) \AA, b=39.0426(8) \AA, c=7.4976(2) \AA$ for 2 . The X-ray thermodiffraction analysis indicates that $\mathbf{1}$ and $\mathbf{2}$ show a phase transformation corresponding to the dehydration process (Figure 1), by losing the two water molecules coordinated to sodium atom, which is a re- 
versible process involving a spontaneous rehydration after cooling down to room temperature, which has been seen clearly in the thermodiffractogram of $\mathbf{1}$ (blue curve at $25^{\circ} \mathrm{C}$ down, Figure 1a), however, it is slowly reversible in the case of $\mathbf{2}$, and takes few days in air after the end of the experiment.
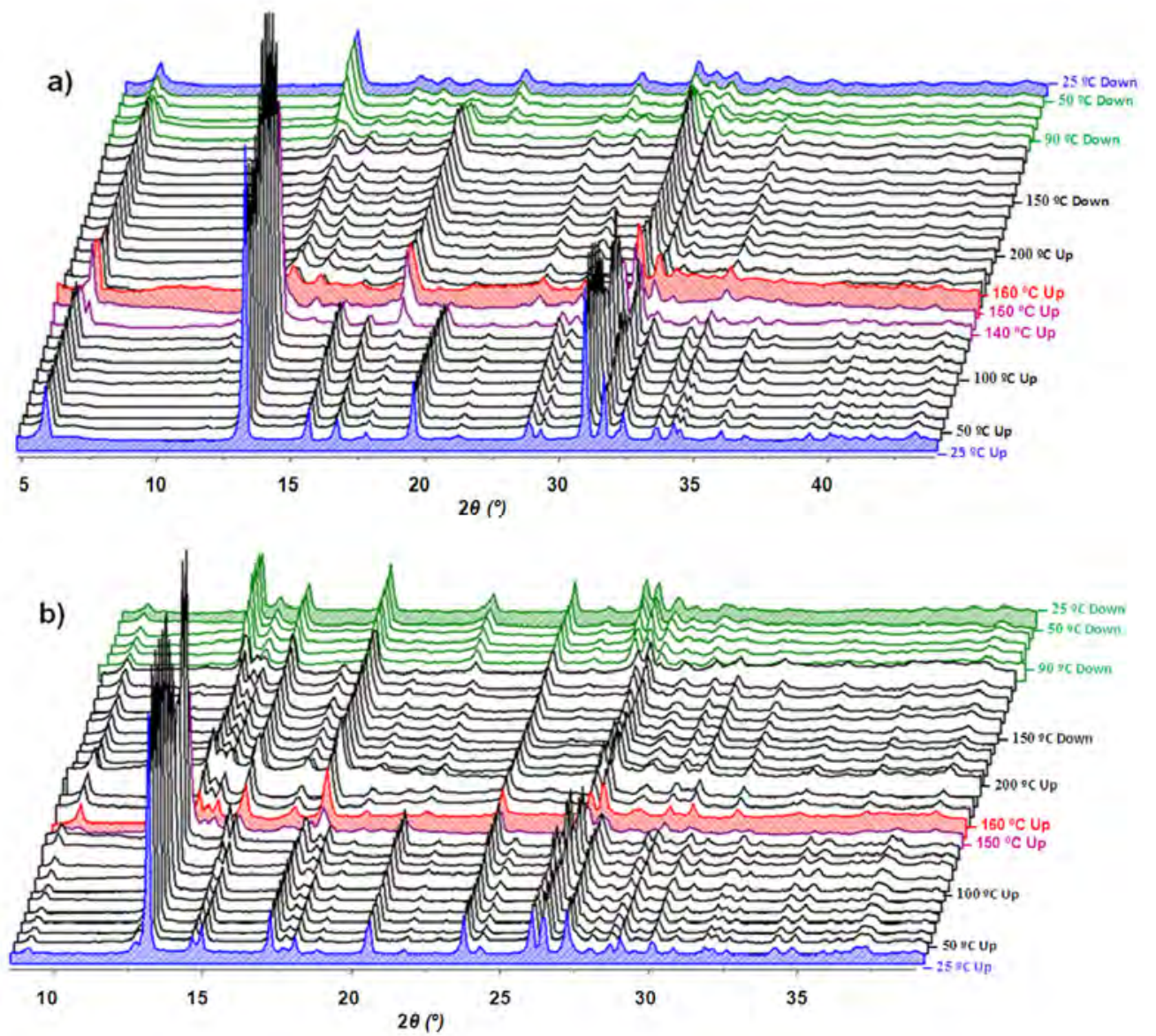

Figure 1. X-ray thermodiffractograms of 1 (a) and 2 (b) recorded in air heating up from $25^{\circ} \mathrm{C}$ to 200 ${ }^{\circ} \mathrm{C}$ and cooling down to $25^{\circ} \mathrm{C}$. Colour code corresponding to the structural changes, blue: compound 1 or 2, purple: dehydration of compound 1 or 2, red: dehydrated compound 1 or 2, green: rehydration of compound 1 or 2 , blue: rehydrated compound 1 .

Since the dehydration of 1 and 2 begins respectively at $140{ }^{\circ} \mathrm{C}$ and $150{ }^{\circ} \mathrm{C}$, the variation of the unit cell parameters of $\mathbf{1}$ and 2 from $50{ }^{\circ} \mathrm{C}$ to $130{ }^{\circ} \mathrm{C}$ (for $\mathbf{1}$ ), and from $50{ }^{\circ} \mathrm{C}$ to $140{ }^{\circ} \mathrm{C}$ (for 2), obtained by Rietveld refinement using the structural models of $\mathbf{1}$ and $\mathbf{2}$ (hydrated), are illustrated in Figure 2 (a) and (b), respectively. A slight contraction of the cell volume of ca. $1 \%$ has been observed from room temperature to $130{ }^{\circ} \mathrm{C}$. The powder XRD pattern of dehydrated compounds, 1 and 2, treated at $200{ }^{\circ} \mathrm{C}$ in air, have been indexed in the orthorhombic system with these unit cell parameters: $a=6.7515(5) \AA, b=28.666(6) \AA$, $c=$ 7.309(1) $\AA, V=1414.5(4) \AA^{3}$, in the case of 1, and $a=6.7195(3) \AA, b=37.886(4) \AA, c=$ 
7.5429(6) $\AA, V=1920.2(3) \AA^{3}$, in the case of 2, by using respectively, TREOR $(\mathrm{M}(20)=18)$ and DICVOL $(\mathrm{M}(20)=21.7)$. The results reveal that the structure of $\mathbf{1}$ and $\mathbf{2}$ contract of ca. $5.6 \%$ and $3 \%$ along the $b$-axis, and the cell volume of $c a .10 \%$ and $5 \%$, respectively, maintaining the orthorhombic crystal system.

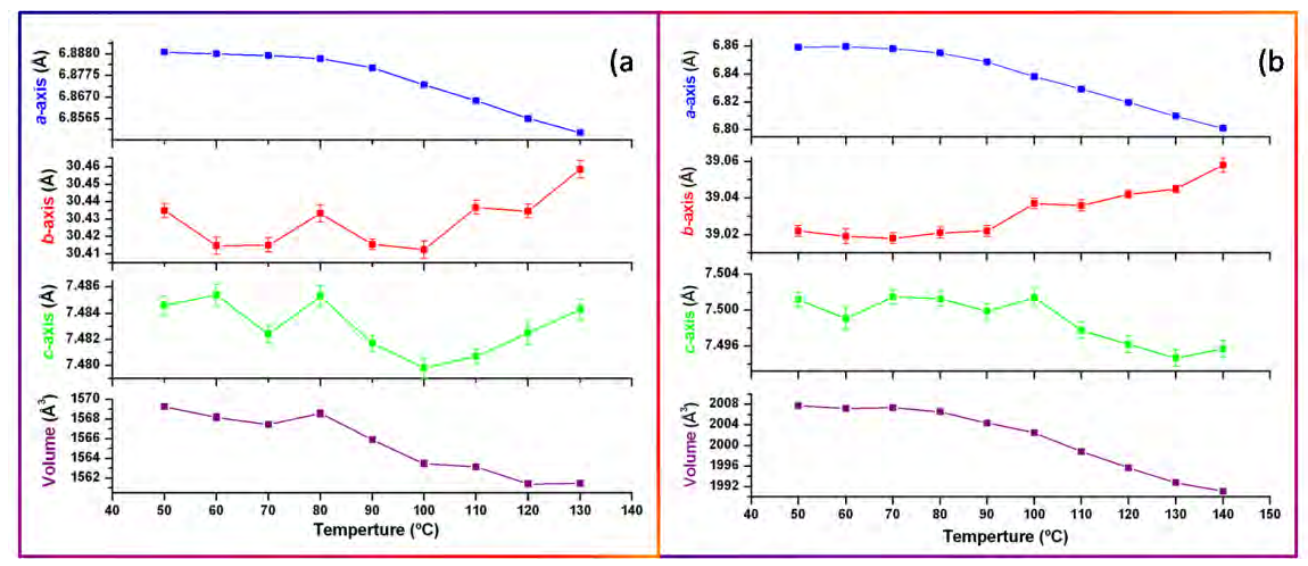

Figure 2. The variation of the unit cell parameters of compound 1 (a) and 2 (b), from $50^{\circ} \mathrm{C}$ to $140{ }^{\circ} \mathrm{C}$.

The attempts for Rietveld refinement of $\mathbf{D 1}$ and $\mathbf{D 2}$ (after removing water molecules from the initial structural models of $\mathbf{1}$ and $\mathbf{2}$ and using the corresponding unit cell parameters found previously for D1 and D2) have been failed, we suspect that the space group have been changed from the centrosymmetric $\mathrm{C} 222_{1}$ to a primitive. Also, ab-initio structural resolution was not reached due to the low quality of powder patterns. Moreover, in-situ variable temperature single-crystal XRD studies were not able to determine the structures of the dehydrated forms, due to the single-crystal deterioration. Thus finally, we resorted to structural modeling. Herein, we have presented the D1 and D2 models obtained by LDA as described in the Section 2.3. The Rietveld refinements of the obtained models have been performed. Cell parameters and refinement indexes of agreement are represented in Table 1. The observed (black) and calculated (blue) profiles for the final Rietveld refinement are showed in the Figure 3. The relative differences of peak intensities between the experimental patterns at $200{ }^{\circ} \mathrm{C}$ and the simulated from the models, and disappearance of some peaks in the models, but not the Bragg-peak positions (Figure 3, red arrows), reflected by the high values of refinement indexes of agreement, may be explained by the fact that an important factor not taken into consideration (not included during the calculation of the models), the temperature factor, supposing that may lead to disorder of the phenyl rings and uncoordinated carboxylate groups (specially in case of dehydrated compound 2, which exhibits the large difference between the experimental and simulated patterns). Given the fact that the disorder is difficult to model, to summarize, the models obtained at this stage are considered quite satisfactory. 

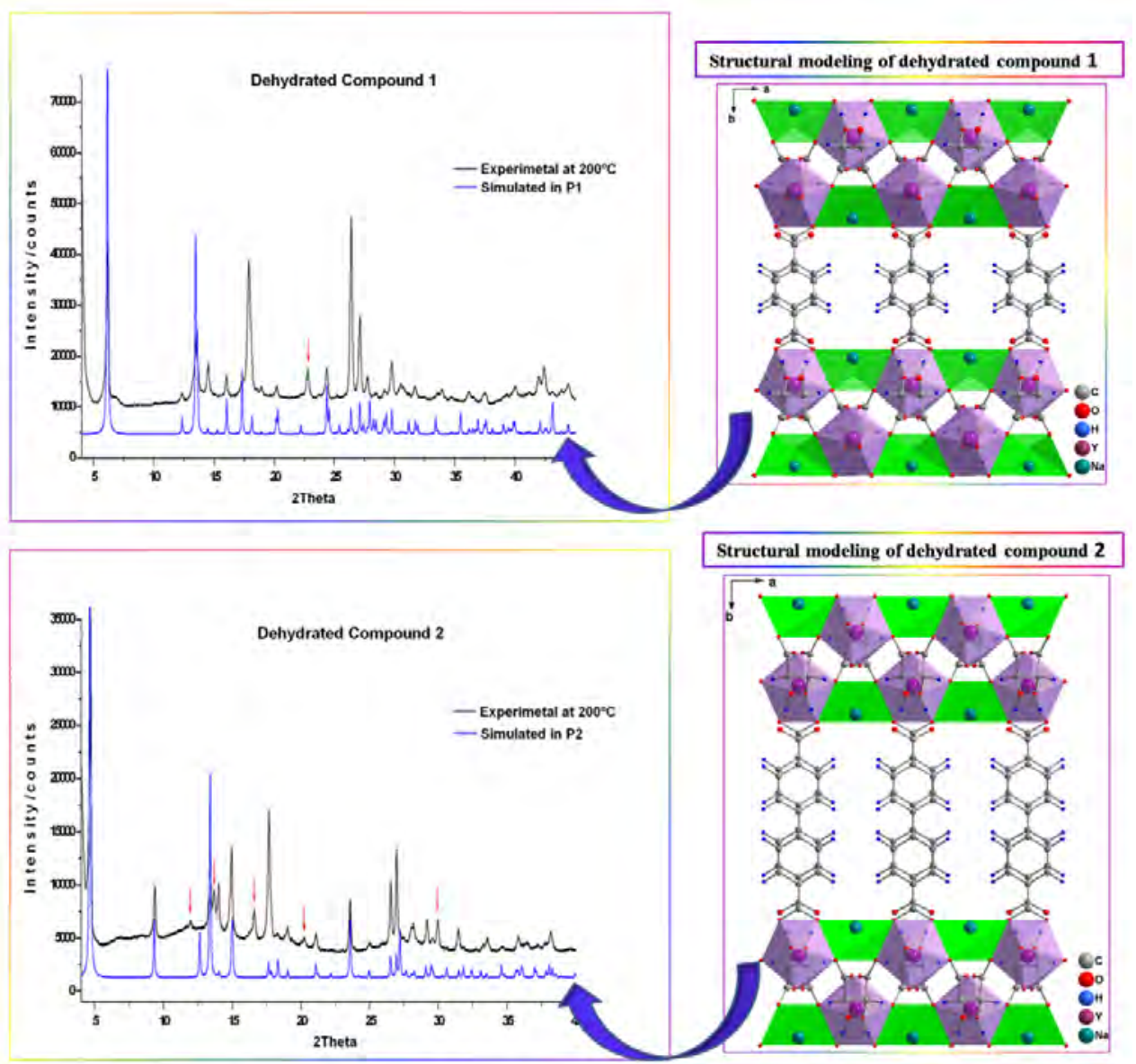

Figure 3. PXRD patterns of dehydrated compounds 1 and 2 at $200{ }^{\circ} \mathrm{C}$ compared with the simulated from the structural modelling.

Table 1. Crystal data and structure refinements for 1 and 2 dehydrated compounds.

\begin{tabular}{|l|c|c|}
\hline & Dehydrated 1 & Dehydrated 2 \\
\hline Formula & $\mathrm{NaY}\left(\mathrm{C}_{4} \mathrm{H}_{4} \mathrm{O}_{6}\right)\left(\mathrm{C}_{8} \mathrm{H}_{4} \mathrm{O}_{4}\right)$ & $\mathrm{NaY}\left(\mathrm{C}_{4} \mathrm{H}_{4} \mathrm{O}_{6}\right)\left(\mathrm{C}_{14} \mathrm{H}_{8} \mathrm{O}_{4}\right)$ \\
\hline Crystal system & Triclinic & Monoclinic \\
\hline Space group & $P 1$ & $P 2$ \\
\hline $\boldsymbol{a}(\AA)$ & $6.75(1)$ & $7.58(1)$ \\
\hline $\boldsymbol{b}(\AA)$ & $28.68(4)$ & $6.718(9)$ \\
\hline $\boldsymbol{c}(\AA)$ & $7.308(9)$ & $37.91(5)$ \\
\hline $\boldsymbol{\alpha}\left(^{\boldsymbol{o}}\right)$ & $89.7(1)$ & 90 \\
\hline $\boldsymbol{\beta}\left(^{{ }^{\circ}}\right)$ & $89.7(1)$ & $85.89(6)$ \\
\hline$\gamma\left(^{{ }^{*}}\right)$ & $89.8(2)$ & 90 \\
\hline $\boldsymbol{R}_{\boldsymbol{p}}$ & 0.136 & 0.0947 \\
\hline $\mathbf{R}_{\mathrm{wp}}$ & 0.219 & 0.1479 \\
\hline
\end{tabular}




\section{Conclusions}

The phase transformation, corresponding to the dehydration process of compounds $\mathbf{1}$ and $\mathbf{2}$, has been confirmed by X-ray thermodiffraction analysis. The low quality of the patterns corresponding to dehydrated compounds prevents $a b$-initio structural resolution of the dehydrated forms of 1 and 2. In-situ variable temperature single-crystal XRD studies, were not able to determine the structures of the dehydrated forms, due to the single-crystal deterioration, The structural modeling of the dehydrated form of $\mathbf{1}$ or $\mathbf{2}$ has been performed using LDA approach, and the best models obtained so far have been presented.

\section{References}

1. Kaye, S.S., Dailly, A., Yaghi, O.M. \& Long, J.R., 2007, J. Am. Chem. Soc., 129, 14176.

2. Collins, D.J. \& Zhou., H.C., 2007, J. Mater. Chem., 17, 3154.

3. Corma, A., Gracía, H. \& Llabrés i Xamena, F.X., 2010, Chem. Rev., 110, 4606.

4. Wang, Z., Hu, K., Gao, S. \& Kobayashi, H., 2010, Adv. Mater., 22, 1526.

5. Rogez, G., Viart, N. \& Drillon, M., 2010, Angew. Chem. Int. Ed., 49, 1921.

6. Liu, K., You, H., Zheng, Y., Jia, G., Song, Y., Huang, Y., Yang, M., Jia, J., Guo, N. \& Zhang, H., 2010, J. Mater. Chem., 20, 3272.

7. Wang, M.S., Guo, S.P., Li, Y., Cai, L.Z., Zou, J.P., Xu, G., Zhou, W.W., Zheng, F.K. \& Guo, G.C., 2009, J. Am. Chem. Soc., 131, 13572.

8. Gustafsson, M., Bartoszewicz, A., Martín-Matute, B., Sun, J., Grins, J., Zhao, T., Li, Z., Zhu, G. \& Zou, X., Chem. Mater., 22, 3316.

9. Shi, F.N., Cunha-Silva, L., Sa Ferreira, R.A., Mafra, L., Trindade, T., Carlos, L.D., Almeida Paz, F.A. \& Rocha, J., 2008, J. Am. Chem. Soc., 130, 150.

10. Wu, C.D. \& Lin, W., 2005, Angew. Chem. Int. Ed., 44, 1958.

11. Amghouz, Z., Roces, L., García-Granda, S., García, J.R., Souhail, B., Mafra, L., Fanian, S. \& Rocha, J., 2010, Inorg. Chem., 49, 7917.

12. http://accelrys.com/products/materials-studio/.

13. Vosko, S.H., Wilk, L. \& Nusair, M., 1980, Can. J. Phys., 58, 1200.

Acknowledgements: Financial support given by Spanish MICINN (MAT2006-01997, MAT2010-15094, Factoría de Cristalización-Consolider Ingenio 2010 and FPI grant BES2007-14340 to Z. A.) and FEDER founding, are acknowledged. 